\title{
Fatores chave para o alinhamento estratégico vertical: Survey com executivos brasileiros
}

\author{
Vanderli Correia Prieto ${ }^{\text {a* }}$, Marly Monteiro de Carvalho ${ }^{\mathrm{b}}$ \\ a*Universidade Federal do ABC, São Bernardo do Campo, SP, Brasil, vanderli.prieto@ufabc.edu.br

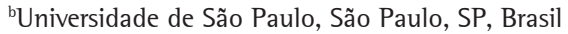

\begin{abstract}
Resumo
0 alinhamento é um conceito central nos estudos sobre estratégia, no entanto as pesquisas dão maior ênfase ao assunto no contexto da formulação do que no da implementação da estratégia. Este estudo contribui para suprir essa lacuna ao identificar e propor um framework com fatores chave para o alinhamento estratégico vertical internamente à organização. Esses fatores foram submetidos a 125 executivos brasileiros, por meio de um estudo quantitativo, para avaliar a sua implementação. Os resultados foram analisados utilizando-se estatística descritiva. Verificou-se que tem sido dada maior ênfase no planejamento de curto prazo e que existe necessidade de ampliar a participação da média gerência na formulação. Os resultados também apontam lacunas nas capacidades gerenciais para a implementação da estratégia e nos fatores que podem aumentar o envolvimento das pessoas com a estratégia.
\end{abstract}

Palavras-chave

Alinhamento estratégico. Alinhamento estratégico vertical. Estratégia empresarial. Implementação da estratégia.

\section{Introdução}

Devido à abrangência das variáveis envolvidas nos estudos da área de estratégia, diferentes taxonomias são empregadas em pesquisas envolvendo o conceito de alinhamento (Venkatraman \& Camillus, 1984). Nesse sentido, a literatura distingue entre alinhamento externo e interno e entre alinhamento vertical e horizontal.

Os estudos sobre o alinhamento externo relacionam-se à formulação da estratégia e tratam do ajuste da organização ao seu ambiente de atuação. Tais estudos têm dominado as pesquisas, uma vez que a prioridade de pesquisadores e executivos tem sido a formulação, em detrimento da implementação da estratégia (Atkinson, 2006; Hrebiniak \& Joyce, 2001; Zajac et al., 2000). Em contraste, o foco do alinhamento interno é a implementação, que compreende o ajuste entre a estratégia e as variáveis internas (Venkatraman \& Camillus, 1984).

0 alinhamento interno envolve o ajuste da organização em duas dimensões, a vertical e a horizontal. 0 alinhamento horizontal envolve a compreensão das necessidades do cliente e o alinhamento dos processos (interfuncionais) capazes de entregar o que o cliente necessita. 0 foco deste artigo é o alinhamento vertical, conceituado como o conjunto de ações necessárias à implementação da estratégia, desde a estratégia formulada até o seu desdobramento por todos os níveis da organização (Prieto, 2011).

Entre o alinhamento vertical e o alinhamento horizontal, o primeiro tem recebido consideravelmente maior atenção por parte da literatura, como indica uma survey realizada por Kathuria et al. (2007). Esses autores também verificaram que a maioria desses estudos explora o alinhamento entre a estratégia de negócios e uma determinada área funcional (Manufatura, Operações, Marketing, Sistemas de Informação), buscando identificar se o alinhamento vertical existe ou não, ou, então, exploram o impacto do alinhamento, em um conjunto específico dessas unidades funcionais, sobre o desempenho. Uma possivel justificativa para esse tipo de estudo é o fato de ser fácil de conceituar, permitindo que a pesquisa seja conduzida na área de especialização do pesquisador (Kathuria et al., 2007). 
A implementação da estratégia, no entanto, envolve o ajuste entre vários elementos organizacionais em um período de tempo mais amplo do que o da elaboração da estratégia (Carvalho et al., 2013; Hrebiniak \& Joyce, 2001). Os executivos se ressentem da dificuldade de promover o alinhamento estratégico e faltam pesquisas indicando quais ações devem ser colocadas em prática. São poucos os modelos de alinhamento estratégico que existem, eles oferecem diferentes visões a respeito do alinhamento e nem todos foram testados empiricamente (Prieto et al., 2009).

Este estudo pretende contribuir para o preenchimento das lacunas apontadas primeiramente identificando, por meio de uma revisão de literatura sistematizada, quais fatores devem ser considerados para promover o alinhamento estratégico vertical. Esses fatores serão organizados em um framework teórico, que deverá considerar a integração dos elementos. Trata-se, portanto, de uma abordagem que vai além da perspectiva bivariada comumente aplicada nos estudos. Uma pesquisa quantitativa será conduzida junto aos gestores para avaliar o grau de implementação dos fatores envolvidos no alinhamento.

Este estudo também é importante porque as pesquisas indicam que fortalecer 0 alinhamento resulta em melhor desempenho organizacional (Monteiro de Barros, 2007; Prieto, 2011).

Este artigo, além da introdução, envolve mais quatro seções: apresentação do framework proposto e dos fatores envolvidos no alinhamento vertical, descrição dos aspectos metodológicos, apresentação dos resultados e considerações finais, incluindo as contribuições do estudo e sugestão para estudos futuros.

\section{Alinhamento estratégico vertical}

Esta seção conceitua o alinhamento estratégico vertical e estabelece um framework teórico que define os fatores envolvidos no alinhamento e a relação entre eles. Cada um dos fatores e a sua contribuição para o alinhamento também são definidos.

\subsection{Alinhamento estratégico vertical}

0 alinhamento interno refere-se à mobilização dos recursos, tangiveis ou intangiveis, para implementação da estratégia formulada. As suas raizes teóricas estão na literatura de implementação da estratégia e de mudança organizacional (Venkatraman \& Camillus, 1984). A proposição de Chandler (1962) sobre o alinhamento da estrutura à estratégia é seminal nesse campo de estudos. Também são relevantes os trabalhos que surgiram nos anos 1970 com a visão da organização baseada em recursos (RBV), com destaque para Galbraith (1977), Miles \& Snow (1978) e Peters \& Waterman (1982).
0 alinhamento interno também é visto como conjunto de atividades inter-relacionadas ou como configurações.

Segundo Siggelkow (2002), o termo configuração usualmente implica que os elementos centrais são reforçados, de maneira que o sistema como um todo está em um estado de coerência ou consistência, portanto o alinhamento interno não deveria ser pensado como associações entre variáveis, mas como configurações, descrevendo conjuntos de elementos e seus relacionamentos. Em contraste, um sistema organizacional pode bem consistir em elementos centrais que não se reforçam um ao outro.

0 conceito de alinhamento estratégico vertical está atrelado ao da operacionalização da estratégia em diferentes níveis organizacionais. É amplamente aceito pela literatura que a estratégia é elaborada em três níveis distintos da organização, envolvendo a estratégia corporativa, a estratégia de negócios e a estratégia funcional (Ginsberg \& Venkatraman, 1985; Hitt et al., 2008).

Uma estratégia no nível corporativo especifica as ações de empresa ao administrar um grupo de vários negócios que competem em vários mercados de produtos (Hitt et al., 2008). Já a estratégia de negócios diz respeito a como competir eficazmente em uma determinada indústria ou negócio. Nesse sentido, as empresas podem ser guiadas pelas estratégias genéricas para definir e defender a posição estratégica desejada (Hitt et al., 2008).

A estratégia funcional é para unidades funcionais específicas dentro de um negócio, por exemplo, uma estratégia de produção, marketing, finanças, e foca na maximização dos recursos dentro de cada função (Ginsberg \& Venkatraman, 1985).

De acordo com Kathuria et al. (2007), o alinhamento vertical refere-se à configuração das estratégias, objetivos, planos de ação e decisões através dos vários níveis da organização. A orientação estratégica deve fluir do nível corporativo para o nível de negócios, e assim sucessivamente. A implementação da estratégia é essencialmente de cima para baixo, com o objetivo de fazer com que os níveis hierárquicos inferiores estabeleçam estratégias, objetivos e planos que viabilizem a concretização de uma estratégia elaborada em um nível superior. Quando essa coerência é alcançada, diz-se que o alinhamento vertical foi realizado.

\subsection{Fatores envolvidos no alinhamento estratégico vertical}

0 levantamento dos fatores envolvidos no alinhamento foi realizado por meio da análise de estudos empíricos sobre alinhamento estratégico. A base para esta pesquisa foi um levantamento 
efetuado na base de dados Web of Science, por palavra-chave, utilizando os termos "strategic fit", "strategic alignment" e "strategic consensus", e ela foi refinada pelas áreas de interesse: gestão, negócios e engenharia industrial e resultou em um total de 272 artigos. A mesma pesquisa realizada na base de dados Scielo, em português, resultou em 13 artigos.

Foi feita uma revisão inicial por título e resumo buscando-se identificar os artigos que tratavam do alinhamento estratégico vertical, a qual resultou, então, em 121 artigos de interesse.

0 maior número de estudos refere-se à área de Tecnologia da Informação/Sistema de Informação (TI/SI) $(35,2 \%)$, seguidos de estudos relacionados ao consenso estratégico (13,9\%), Operações (11,1\%), Cadeia de Suprimentos (10,2\%), Recursos Humanos $(4,6 \%)$, Medição de Desempenho (3,7\%), alinhamento em empresas multinacionais $(2,8 \%)$ e outras áreas $(18,5 \%)$

Também foram pesquisadas as teses e dissertações produzidas no Brasil e no exterior, utilizando-se, respectivamente, as bases de dados Biblioteca Digital Brasileira de Teses e Dissertações e ProQuest. No exterior foram localizadas 14 teses, sendo duas de alinhamento de pessoas à estratégia e 12 de alinhamento nas áreas de Tecnologia da Informação ou Sistemas de Informação. No Brasil, 35 trabalhos investigam o alinhamento estratégico, sendo das seguintes áreas: Tl/SI (16), Operações (cinco), Recursos Humanos (três) Sistemas de Desempenho (10) e alinhamento estratégico - abordagem baseada em sistemas (um).

Foram identificados diferentes conceitos sobre alinhamento vertical em estudo: alinhamento entre a estratégia de negócios e a área de operações (ex.: Hill \& Cuthberthson, 2011; Joshi et al., 2003; Prieto \& Carvalho, 2011); alinhamento dos recursos humanos à estratégia de negócios (ex.: Boswell, 2006); alinhamento estratégico em empresas multinacionais (ex.: White et al., 2013; Xu et al., 2006); consenso estratégico: (ex.: Camelo et al., 2010; Floyd \& Wooldridge, 1992a; Gonzalez-Benito et al., 2012; Kellermanns et al., 2011; Wooldridge \& Floyd, 1990); alinhamento estratégico de sistema de informação: (ex.: Asato et al., 2011; Chan et al., 2006; Chen et al., 2010); alinhamento dinâmico (ex.: Kraatz \& Zajac, 2001; Zajac et al., 2000); alinhamento entre sistemas de atividades (ex.: Carmeli \& Tishler, 2004; Siggelkow, 2001, 2002; Zaefarian et al., 2013); alinhamento entre a sustentabilidade e a estratégia (ex. Oliveira et al., 2012).

Os fatores envolvidos no alinhamento estratégico identificados nos trabalhos foram confrontados com a delimitação do conceito de alinhamento vertical aplicado neste estudo: “[...] conjunto de ações necessárias à implementação da estratégia, desde a estratégia formulada até o seu desdobramento por todos os níveis da organização [...]” (Prieto, 2011, p. 30), o que resultou na seleção dos fatores, os quais foram organizados no framework representado na Figura 1. Dessa forma, as variáveis selecionadas denotam um processo que vai desde a definição da estratégia até a compreensão e realização dela pelas pessoas.

As variáveis processo formal de planejamento, envolvimento da média gerência na formulação e consenso sobre a estratégia fazem parte de um mesmo processo, aqui denominado abrangência da formulação da estratégia, que compreende os aspectos da formulação que influenciarão o processo de implementação.

Segue-se a definição dos fatores selecionados e a sua relação com o alinhamento estratégico vertical.

\subsubsection{Processo Formal de Planejamento (PFP)}

0 PFP compreende a existência de um processo de planejamento estratégico estabelecido.

A existência de um processo formal de planejamento está associada à formalização da estratégia, para posterior comunicação aos responsáveis pela implementação e acompanhamento da realização. $\mathrm{Na}$ dinâmica do processo de transformação da estratégia em ação, a formulação de um plano continua sendo o seu ponto inicial (Mintzberg, 1994).

Nesse sentido é que, por exemplo, o Balanced Scorecard tem alcançado uma grande aceitação entre teóricos e práticos (Neely, 2005; Speckbacher et al., 2003). Enquanto sistema de alinhamento estratégico, o modelo apoia-se em dois eixos principais, o da comunicação e o do controle da estratégia, tendo como elemento central justamente a formalização da estratégia por meio do mapa estratégico (Kaplan \& Norton, 1996, 2000).

Labovitz \& Rosansky (1997) apresentam uma proposta semelhante ao BSC para o alinhamento estratégico, por meio do desdobramento da estratégia em um sistema de métricas. 0 processo inicia-se com a definição ou revisão do propósito essencial e, a partir daí, são definidos, em uma estrutura em árvore, indicadores críticos de sucesso, metas, atividades e táticas. Cada departamento ou unidade tem a sua própria árvore ligada a um nível hierarquicamente superior, sendo que o que é uma meta para uma unidade torna-se o propósito essencial para uma unidade que ocupa um nível abaixo.

No modelo proposto por Hambrick \& Cannella Junior (1989) são definidas etapas a serem conduzidas 


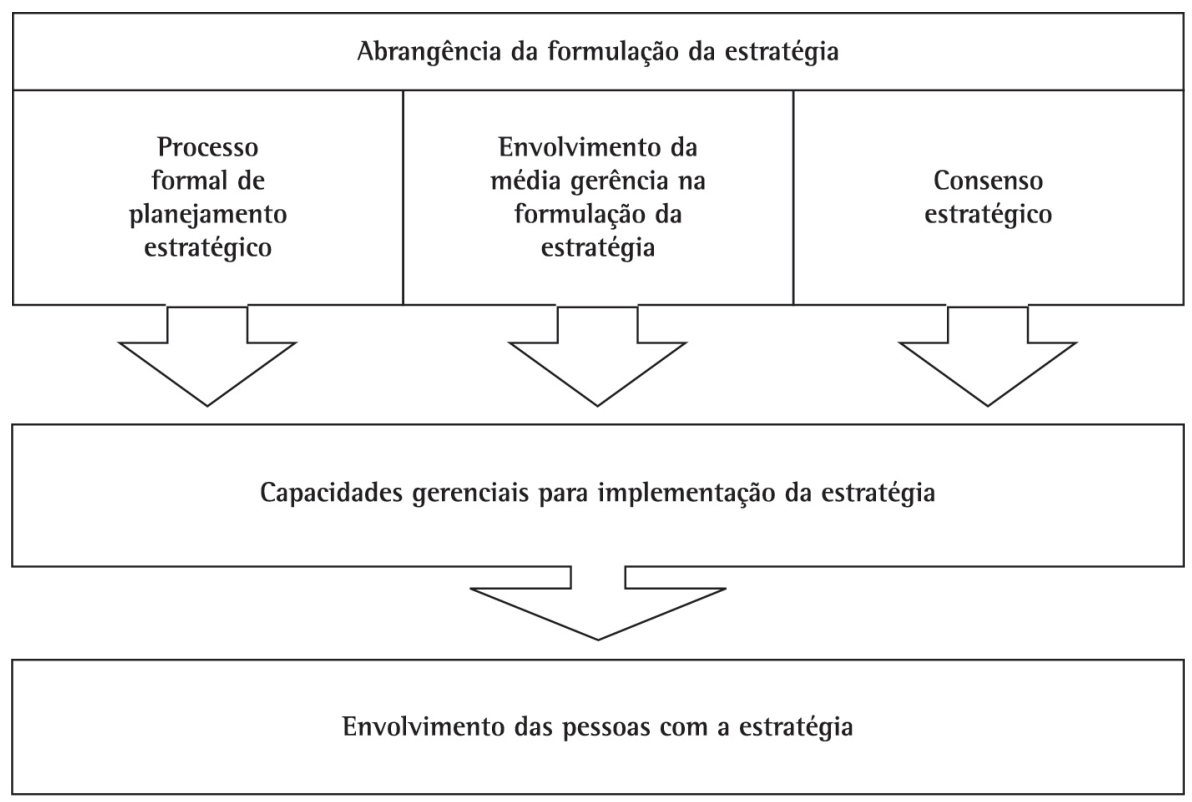

Figura 1. Fatores chave para o alinhamento estratégico vertical.

pelo próprio executivo, desde a formulação até a implementação da estratégia. A primeira delas é uma "preparação de terreno" para a nova estratégia, que inclui aspectos da formulação da estratégia, como uma amplitude de entradas e tratamento cuidadoso dos obstáculos de implementação.

Fatores relacionados à formalização do planejamento afetam o conhecimento compartilhado entre os executivos a respeito da estratégia (Chan et al., 2006), que por sua vez afetam o comprometimento organizacional e o desempenho individual dos gestores, podendo comprometer o sucesso na implementação de estratégias (Noble \& Mokwa, 1999; Wong et al., 2012).

\subsubsection{Envolvimento da Média Gerência na formulação (EMG)}

O EMG compreende a participação da média gerência na formulação da estratégia e no processo posterior de implementação.

A teoria contemporânea sobre decisão estratégica considera que o papel da média gerência vai além do tradicional fornecimento de informações de entrada e condução do processo de implementação para o de influenciar regularmente a estratégia e prover o impulso para novas iniciativas (Floyd \& Wooldridge, 1992a; Mintzberg \& Waters, 1985).

Apesar de a média gerência não ter necessariamente o perfil requerido de um estrategista, o conhecimento das operações diárias e a gestão de linha de frente do negócio são fontes importantes para a inovação estratégica, sendo que a probabilidade dessas ideias emergirem é maior no processo criativo de formulação da estratégia (Campbell \& Alexander, 1997).

Outros argumentos favoráveis à participação da média gerência na formulação dizem respeito à necessidade de se planejar e analisar os ajustes necessários à implementação já nessa fase, para se ter certeza de que a estratégia é viável (Hambrick \& Cannella Junior, 1989); ela também ajuda a determinar o seu papel na implementação e tem relação com o comprometimento individual em relação aos objetivos e metas estabelecidos (Decoene \& Bruggeman, 2006; Noble \& Mokwa, 1999); está ainda associada à melhoria do desempenho organizacional (Wooldridge \& Floyd, 1990).

Em relação às atividades de implementação da estratégia, a atuação da média gerência dá-se no sentido de alinhar as ações organizacionais com as intenções estratégicas, por meio da intervenção na estrutura, pessoas e sistemas (Floyd \& Wooldridge, 1992b).

\subsubsection{Consenso Estratégico (CE)}

0 CE envolve o quanto os gestores compreendem e dão suporte à estratégia da empresa.

Existem várias dimensões do consenso sendo abordadas em pesquisas empíricas no campo da estratégia (Kellermanns et al., 2011). A dimensão do consenso que se pretende explorar neste trabalho é 
a do comprometimento estratégico, definido como a compreensão e suporte, por parte do gerente, para o alcance das metas da organização (Noble \& Mokwa, 1999) ou, ainda, definido como o acordo entre a alta direção e os gerentes de nível médio e operacional sobre as prioridades da organização (Floyd \& Wooldridge, 1992b).

Nos modelos empíricos propostos por Noble \& Mokwa (1999) e Parish et al. (2008), a estratégia é considerada um dos antecedentes do comprometimento estratégico e o sucesso na sua implementação, uma das suas consequências. 0 comprometimento dos gestores com a implementação é afetado pela importância atribuída à estratégia, que depende da percepção dos gestores quanto ao impacto da estratégia sobre os negócios (Noble \& Mokwa, 1999). Em geral, o comprometimento com a estratégia depende da percepção dos gestores quanto ao seu alinhamento com os interesses da organização e da percepção do quanto ela se alinha a seus próprios interesses (Floyd \& Wooldridge, 1992b).

Outros fatores também afetam o consenso, tais como: frequente comunicação vertical entre os altos executivos e os gerentes operacionais (Rapert et al., 2002), conhecimento compartilhado sobre a estratégia entre a alta gerência e os executivos do nível funcional (Chan et al., 2006).

\subsubsection{Capacidades Gerencias para a implementação da estratégia (CG)}

Capacidades Gerenciais abrange as capacidades requeridas dos executivos para promover o alinhamento estratégico.

A habilidade de efetivamente implementar a estratégia pode ser, em si mesma, uma fonte de vantagem competitiva (Fleury \& Fleury, 2000; Grant, 1991; Malina \& Selto, 2001; Powell, 1992). Powell (1992) argumenta que o alinhamento requer que o executivo demonstre uma alta capacidade de integração e que a habilidade de alinhamento organizacional poderia ser considerada um recurso estratégico rentável, capaz de melhorar o desempenho organizacional. Nesse mesmo sentido, Barney \& Mackey (2005, p. 9) afirmam que se a habilidade de uma empresa de implementar a estratégia é válida, rara, difícil de imitar, então a capacidade de implementação de estratégias de uma empresa é uma fonte potencial de vantagem competitiva.

A seguir discutem-se as habilidades que são requeridas do executivo para conduzir o alinhamento estratégico.

Para ter sucesso na implementação da estratégia relativa à unidade de negócio que o gestor dirige é necessário ser hábil na coordenação de decisões e ações entre todas as funções (Hitt et al., 1982), uma vez que a comunicação entre diferentes funções é um desafio característico da implementação, devido ao envolvimento de mais pessoas do que na etapa da formulação (Hrebiniak, 2006, p. 31)

Hambrick \& Cannella Junior (1989) atribuem ao estrategista o papel de negociação e convencimento a respeito da estratégia. A ideia é negociar a estratégia interna e externamente à organização com o objetivo de construir e manter o suporte necessário para a sua implementação em meio às resistências que naturalmente surgem devido ao interesse de determinadas partes em manter a velha estratégia ou por falta de compreensão da nova proposta. Nesse processo, o estrategista precisa ter habilidade para identificar os principais obstáculos à implementação da estratégia e se perguntar se realmente ela pode ser operacionalizada antes de colocá-la em ação.

Ainda segundo Hambrick \& Cannella Junior (1989), o gestor tem por papel promover os ajustes nos fatores que são relevantes no processo de implementação, tais como alocação de recursos e ajuste dos programas das subunidades, da estrutura e do sistema de recompensas. Essa afirmação é corroborada por Noble \& Mokwa (1999), para quem a alocação de recursos é utilizada pelos atores envolvidos na implementação como um componente racional para avaliar o comprometimento dos seus superiores com a estratégia, os quais esperam que eles liberem os recursos necessários para a sua eficácia.

Comunicação adequada entre os níveis gerenciais tem sido apontada por vários autores como a chave para obter o entendimento compartilhado sobre as prioridades estratégicas (Noble, 1999; Rapert et al., 2002). A comunicação vertical é pobre quando a cultura da organização não favorece o diálogo aberto entre os níveis hierárquicos e diante da não disposição por parte dos gerentes seniores em confrontar publicamente as barreiras que bloqueiam a implementação da estratégia (Beer \& Eisenstat, 2000, 2004).

\subsubsection{Envolvimento das Pessoas com a estratégia (EP)}

0 EP abrange as condições necessárias para promover um comportamento orientado para o alcance dos objetivos e metas, tais como, cultura e sistema de recompensas e reconhecimento.

Segundo Kaplan \& Norton (2006, p. 295), o alinhamento do capital humano é alcançado quando os objetivos individuais, programas de treinamento e remuneração estiverem alinhados com a estratégia de negócios. 
Vários autores assumem a relação entre a cultura e 0 alcance dos objetivos organizacionais. Para Fleury \& Fleury (1997), uma forte cultura pressupõe o comprometimento dos empregados com os objetivos organizacionais.

Labovitz \& Rosansky (1997) propõem a criação de uma organização capaz de auto alinhar-se. As bases para essa conduta são a liderança, a cultura e um sistema de medidas de desempenho. Os autores acreditam que as medidas moldam o comportamento e o comportamento cria a cultura. Para isso, as medidas têm de fazer sentido para as pessoas e precisam ser apresentadas como tendo relação com o propósito essencial dos negócios e estarem ligadas a um sistema de recompensas e reconhecimento. Ainda segundo os autores, trata-se de uma forma de levar as pessoas a adaptarem o seu comportamento para o alcance das medidas o tempo todo, de forma que o comportamento coletivo das pessoas forma a cultura de autoalinhamento.

A motivação e um sistema que recompense os resultados alcançados pelos indivíduos e unidades organizacionais são essenciais para a eficácia na implementação da estratégia. Para Kaplan \& Norton (2006), a motivação extrínseca deve reforçar a mensagem estratégica e pode ser explorada por meio da remuneração por incentivos devidos ao alcance de metas. Hrebiniak (2006) recomenda que os incentivos estejam vinculados aos objetivos estratégicos ou aos objetivos de curto prazo que derivam da estratégia.

Os gestores encontram dificuldade em ter uma medida precisa sobre o alinhamento que permita mensurar até que ponto os funcionários de fato entendem qual é a estratégia e como contribuem para a sua execução. A despeito dessa dificuldade, uma percepção positiva do alinhamento por parte dos funcionários influencia a sua atitude, o que acontece quando os funcionários acreditam que entendem o que se espera deles e sentem que podem contribuir (Boswell \& Boudreau, 2001).

Resultados de estudos desenvolvidos por Gagnon et al. (2008) demonstram que pessoas comprometidas com a estratégia predispõem-se a engajarem-se em comportamentos que suportam a estratégia e que o desenvolvimento do comprometimento das pessoas com a estratégia provavelmente auxilia nas transformações estratégicas necessárias. 0 estudo também provê evidências sobre o fato de que a liderança tem um papel central no desenvolvimento das atitudes positivas dos funcionários e da confiança, com efeito positivo sobre o comprometimento estratégico.

\section{Aspectos metodológicos}

Considerando-se a estrutura proposta por Creswell (2007), este trabalho emprega o método de pesquisa quantitativo, que usa alegações pós-positivistas para o desenvolvimento do conhecimento, as quais se aplicam a esta pesquisa pela proposição de construtos específicos, processo de investigação com uso de instrumento predeterminado, com posterior geração e avaliação de dados estatísticos.

Dentre as classificações de pesquisa propostas por Forza (2002) trata-se de uma survey exploratória, considerando-se que o alinhamento tem sido conceituado de maneira distinta e tem sido pesquisado em diferentes contextos, exigindo pesquisas exploratórias para aprofundamento do conceito.

0 questionário final (Anexo 1) foi composto por 30 assertivas, organizadas em cinco blocos representando os fatores envolvidos no alinhamento estratégico vertical. Empregou-se a escala ordinal com graus de concordância de 1 (discordo totalmente) a 5 (concordo totalmente). Nesse sentido, a escala ordinal permite ordenar a opinião dos respondentes sobre as afirmações propostas, mas não indica a medida das diferenças entre os rankings, não retratando um valor absoluto (Hair Junior et al., 2009).

Para a construção do questionário foram utilizados, como referência, instrumentos de pesquisa localizados na literatura, os quais estão identificados na Tabela 1.

0 questionário também tinha uma seção, com escala nominal, para coletar dados sobre o perfil da empresa e do respondente. Trata-se de um tipo de escala que pode ser aplicada para identificar as características da amostra em estudo (Hair Junior et al., 2009).

\section{Análise dos dados}

Em uma primeira etapa, os dados obtidos foram analisados buscando-se caracterizar a amostra quanto ao perfil das empresas e dos respondentes, utilizando-se a análise de frequência das respostas. Em seguida procedeu-se à análise preliminar dos dados, quanto aos dados omissos (missing values) e dados discrepantes (outliers).

Foram analisadas as frequências absolutas e relativas dos dados omissos para cada variável da pesquisa, buscando-se analisar a sua aleatoriedade ou não. A variável com maior número de dados omissos foi CG6, representando 1,6\% da amostra. Evidenciou-se, portanto, que a ocorrência de dados omissos é aleatória, não comprometendo a análise dos dados. 0 tratamento adotado para os dados omissos foi a substituição de tais variáveis pelo valor médio dos casos válidos dessa variável, preservando-se, assim, o total da amostra (Hair Junior et al., 2009).

A existência de dados discrepantes (outliers) foi verificada na perspectiva univariada, por meio do teste Kolmogorov-Smirnov, que calcula o nível de significância para as diferenças em relação a uma 
distribuição normal (Hair Junior et al., 2009). A análise não revelou variáveis com valor padronizado acima de três desvios padrões. 0 maior desvio padrão foi 1,365, encontrado na variável PFP6 - Nós temos uma equipe encarregada da elaboração de um plano estratégico formal.

Os testes para tratamento preliminar das variáveis e as estatísticas descritivas foram realizados no software SPSS (Statistical Package for Social Sciences), versão 17.0 .

Para analisar a consistência interna do instrumento, que mede a interrelação entre os itens de uma escala, foi utilizado o tradicional critério desenvolvido por Cronbach \& Meehl (1955), o Alpha de Cronbach, que estima a confiabilidade com base nos indicadores conjuntamente. Os valores estão demonstrados no Anexo 1. Eles foram calculados diretamente por meio do software SPSS e são superiores ao recomendado de 0,7 (Hair Junior et al., 2009).

\section{Amostra}

Utilizou-se uma amostra não probabilística. Os dados foram coletados por meio de um link para acesso on-line e também em papel. A pesquisa foi conduzida com a média gerência ou profissionais diretamente envolvidos com a implementação da estratégia de negócios. Foram coletadas 129 respostas, das quais quatro foram descartadas, uma por preenchimento incorreto dos dados e as outras três por perfil inadequado dos respondentes, resultando em 125 questionários válidos.

A Tabela 2 apresenta o perfil das empresas constantes da amostra por área de atuação e porte.

Tabela 1. Origem das assertivas propostas para os instrumentos de pesquisa.

\begin{tabular}{ll}
\multicolumn{2}{c}{ Construto } \\
\hline Processo Formal de Planejamento & Miller (1987) e Powell (1992) \\
Envolvimento da Média Gerência na Formulação & Noble \& Mokwa (1999) \\
Consenso Estratégico & Noble \& Mokwa (1999) \\
Capacidades Gerenciais para a lmplementação da Estratégia & Hitt \& lreland (1985), Carmeli \& Tishler (2004) e Noble \& Mokwa (1999) \\
Envolvimento das Pessoas com a Estratégia & Carmeli \& Tishler (2004) e Labovitz \& Rosansky (1997). \\
\hline
\end{tabular}

Tabela 2. Caracterização da amostra por área de atuação e porte.

\begin{tabular}{|c|c|c|c|c|c|}
\hline \multirow{2}{*}{ Área de atuação } & \multicolumn{3}{|c|}{ Porte } & \multirow{2}{*}{ Total } & \multirow{2}{*}{$\%$} \\
\hline & Pequena & Média & Grande & & \\
\hline Atividades financeiras e de seguros & 1 & 0 & 25 & 26 & 20,8 \\
\hline Alimentos & 0 & 0 & 3 & 3 & 2,4 \\
\hline Automação, tecnologia & 0 & 1 & 1 & 2 & 1,6 \\
\hline Automotiva & 0 & 5 & 6 & 11 & 8,8 \\
\hline Bens de capital & 0 & 1 & 1 & 2 & 1,6 \\
\hline Bens de consumo & 1 & 1 & 1 & 3 & 2,4 \\
\hline Comércio & 1 & 0 & 0 & 1 & 0,8 \\
\hline Construção civil & 0 & 0 & 5 & 5 & 4,0 \\
\hline Cosméticos & 0 & 1 & 0 & 1 & 0,8 \\
\hline Educação & 0 & 0 & 2 & 2 & 1,6 \\
\hline Eletrônica, eletroeletrônica & 1 & 0 & 5 & 6 & 4,8 \\
\hline Embalagem & 1 & 1 & 2 & 4 & 3,2 \\
\hline Energia & 0 & 0 & 1 & 1 & 0,8 \\
\hline Farmacêutica & 0 & 3 & 2 & 5 & 4,0 \\
\hline Ferramentas de corte & 0 & 1 & 0 & 1 & 0,8 \\
\hline Papel e celulose & 0 & 0 & 2 & 2 & 1,6 \\
\hline Plástico, derivados & 0 & 2 & 1 & 3 & 2,4 \\
\hline Química, petroquímica & 0 & 2 & 4 & 6 & 4,8 \\
\hline Saúde & 0 & 1 & 4 & 5 & 4,0 \\
\hline Serviços de informática, internet & 1 & 2 & 0 & 3 & 2,4 \\
\hline Serviços & 2 & 10 & 9 & 21 & 16,8 \\
\hline Telecomunicação, comunicação & 1 & 1 & 5 & 7 & 5,6 \\
\hline Não informou & 0 & 0 & 0 & 5 & 4,0 \\
\hline TOTAL & 9 & 32 & 79 & 125 & \\
\hline$\%$ & 7,2 & 25,6 & 63,2 & 100,0 & 100,0 \\
\hline
\end{tabular}


$\mathrm{Na}$ amostra predominam as empresas de grande porte $(63,2 \%)$, seguidas pelas empresas de médio porte $(25,6 \%)$, o que é bastante adequado para a pesquisa em questão, pois existe uma tendência de empresas maiores utilizarem instrumentos formalizados de gestão, como é o caso do planejamento formal da estratégia. Predominam as empresas que atuam em atividades financeiras e de seguros $(20,8 \%)$, serviços $(16,8 \%)$ e automotiva $(8,8 \%)$.

A Tabela 3 apresenta o perfil dos respondentes por cargo e área de atuação.

Predominam os diretores e gerentes $(47,2 \%)$, seguidos por supervisores, coordenadores ou analistas $(31,2 \%)$. A amostra foi considerada adequada, uma vez que o perfil dos respondentes é o de pessoas que ocupam cargos tradicionalmente caracterizados pelo envolvimento com a implementação da estratégia.

\section{Apresentação e análise dos resultados}

Inicialmente, os dados serão apresentados e analisados por construto. Também serão analisadas as conexões entre os apontamentos de cada construto, considerando-se as inter-relações propostas no framework teórico (Figura 1).
Para facilitar a sua interpretação, as frequências das assertivas foram agrupadas em três graus de concordância, sendo: discordância (menores ou iguais a dois), neutralidade (igual a três) e concordância (maiores ou iguais a quatro).

\subsection{Processo Formal de Planejamento (PFP)}

A Figura 2 apresenta os dados do construto PFP.

A concordância com a assertiva $1(79,2 \%)$ indica que as ações dessas empresas são baseadas mais em planos formais do que na intuição. Devido à própria composição da amostra, formada por grandes e médias empresas, é de fato esperado que possuam instrumentos formais de gestão.

Evidencia-se que é dada maior ênfase à formalização de metas de curto prazo (PFP3, 79,8\%) do que a um sistema de planejamento estratégico mais amplo, que envolva o desenvolvimento de toda a organização (PFP4, 66,1\%) ou a um planejamento formalizado com antecedência para o exercício seguinte (PFP5, 68\%).

A discordância e neutralidade com relação às assertivas PFP2 $(33,6 \%)$ - objetivos de longo

Tabela 3. Perfil dos respondentes por cargo e área de atuação.

\begin{tabular}{|c|c|c|c|c|c|c|}
\hline \multirow[b]{2}{*}{ Área de atuação } & \multicolumn{5}{|c|}{ Cargo } & \multirow[b]{2}{*}{ Total } \\
\hline & $\begin{array}{c}\text { Presidente/ } \\
\text { Vice- presidente }\end{array}$ & $\begin{array}{l}\text { Diretor/ } \\
\text { gerente }\end{array}$ & $\begin{array}{c}\text { Supervisor/ } \\
\text { coordenador analista }\end{array}$ & Consultor & $\mathrm{N1}$ & \\
\hline Atividades financeiras e de seguros & 2 & 9 & 13 & 1 & 1 & 26 \\
\hline Alimentos & 0 & 0 & 0 & 0 & 3 & 3 \\
\hline Automação, tecnologia & 0 & 0 & 2 & 0 & 0 & 2 \\
\hline Automotiva & 1 & 7 & 2 & 0 & 1 & 11 \\
\hline Bens de capital & 0 & 1 & 1 & 0 & 0 & 2 \\
\hline Bens de consumo & 0 & 2 & 0 & 0 & 1 & 3 \\
\hline Comércio & 0 & 1 & 0 & 0 & 0 & 1 \\
\hline Construção civil & 0 & 3 & 1 & 0 & 1 & 5 \\
\hline Cosméticos & 0 & 1 & 0 & 0 & 0 & 1 \\
\hline Educação & 0 & & 2 & 0 & 0 & 2 \\
\hline Eletrônica, eletroeletrônica & 0 & 3 & 3 & 0 & 0 & 6 \\
\hline Embalagem & 0 & 2 & 0 & 0 & 2 & 4 \\
\hline Energia & 0 & & 0 & 0 & 1 & 1 \\
\hline Farmacêutica & 0 & 5 & 0 & 0 & 0 & 5 \\
\hline Ferramentas de corte & 0 & 1 & 0 & 0 & 0 & 1 \\
\hline Papel e celulose & 0 & 2 & 0 & 0 & 0 & 2 \\
\hline Plástico, derivados & 0 & 2 & 1 & 0 & 0 & 3 \\
\hline Química, petroquímica & 0 & 1 & 4 & 0 & 1 & 6 \\
\hline Saúde & 0 & 2 & 2 & 0 & 1 & 5 \\
\hline Serviços de informática, internet & 0 & 3 & 0 & 0 & 0 & 3 \\
\hline Serviços & 1 & 11 & 5 & 2 & 2 & 21 \\
\hline Telecomunicação, comunicação & 0 & 3 & 3 & 0 & 1 & 7 \\
\hline Não informou (NI) & 0 & 0 & 0 & 0 & 5 & 5 \\
\hline Total & 4 & 59 & 39 & 3 & 15 & 125 \\
\hline$\%$ & 3,2 & 47,2 & 31,2 & 2,4 & 12,0 & 100,0 \\
\hline
\end{tabular}

$\mathrm{Nl}$ - não informou. 


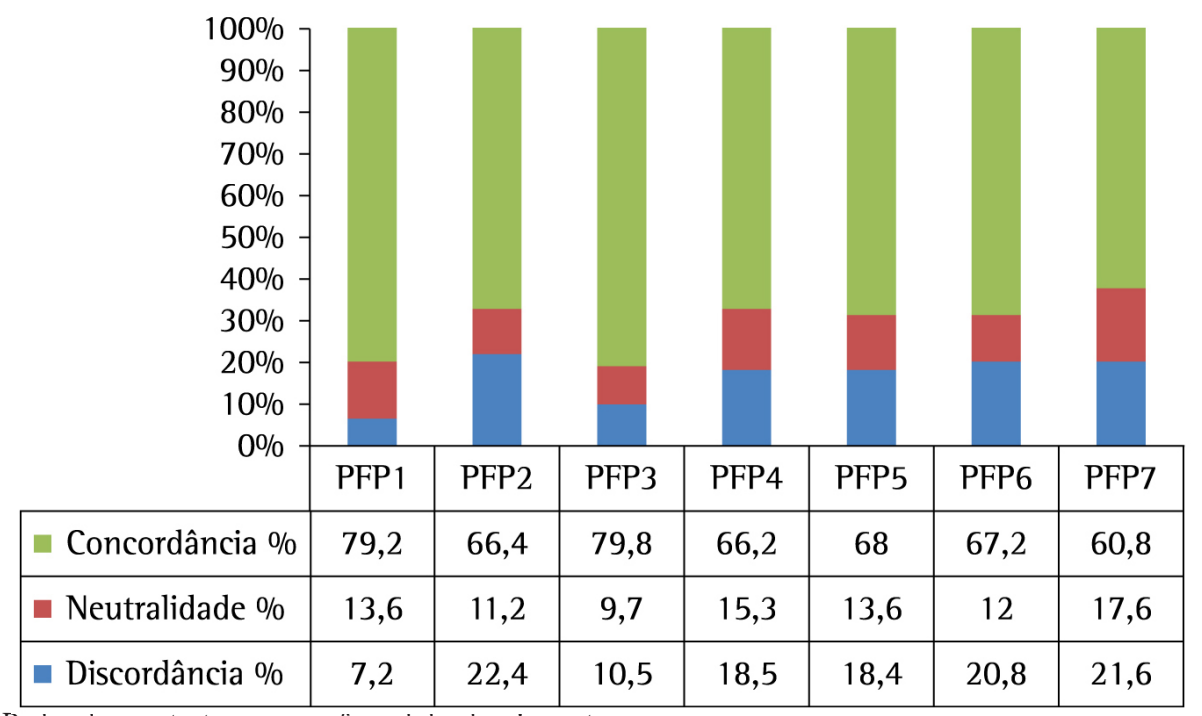

Figura 2. Dados do construto processo formal de planejamento.

prazo conhecidos por todos os gerentes e PFP7 $(39,2 \%)$ - manutenção de encontros gerenciais regulares para discutir a estratégia são indícios de problemas de comunicação ou da baixa participação da média gerência no processo estratégico.

Analisando-se os dados conjuntamente, pode-se inferir que a natureza do planejamento, voltado para resultados mais imediatos e que requer que as ações sejam colocadas em prática em espaço de tempo mais curto, pode ser a causa da centralização do planejamento nos níveis hierárquicos superiores.

\subsection{Envolvimento da média gerência na formulação}

Conforme pode ser visualizado na Figura 3, os respondentes concordam que a média gerência é peça chave para a implementação da estratégia (EMG5 - 75,2\%) e que suas responsabilidades nesse contexto são significativas (EMG4 - 74,4\%).

As três primeiras assertivas medem a participação da média gerência na definição das atividades de implementação. Nesse sentido, 48,8\% dos respondentes afirmam tomar conhecimento da estratégia antes da sua implementação (EMG2). No entanto, 63,2\% (EMG1) trabalham junto com seus superiores para decidir o que será feito em termos das atividades de implementação e 62,4\% (EMG3) sentem que podem procurar seus superiores para sugerir mudanças nessas atividades quando a estratégia já está em ação.

Esses percentuais podem ser indicativos de que a média gerência tem maior participação na definição das atividades de implementação do que na definição da estratégia em si.

A baixa participação da média gerência na atividade de formulação pode ter relação com a formulação de planos de curto prazo, como evidenciado no construto anterior.

\subsection{Consenso Estratégico (CE)}

As estatísticas descritivas do construto CE são apresentadas na Figura 4.0 percentual de concordância com relação às assertivas em geral indica que os respondentes consideram que a estratégia em ação em sua empresa é relevante para a realização da missão da empresa (CE1 - 82,4\%) e pode afetar positivamente o futuro dos negócios (CE2 - 89,6\%).

No entanto, quando questionados se pessoalmente estão de acordo com os objetivos relacionados à estratégia em ação (CE4), o grau de concordância é menor $(76,8 \%)$ do que com relação às outras assertivas que mensuram a opinião dos respondentes sobre a importância da estratégia para os negócios em si.

A análise conjunta dos dados apresentados até o momento demonstra que há relação entre a natureza do planejamento, o grau de envolvimento da média gerência e o consenso individual desses com relação aos objetivos estratégicos delineados. Os dados corroboram a afirmação teórica de que a participação da média gerência na formulação tem relação com o comprometimento individual em relação aos objetivos e metas estabelecidos (Noble \& Mokwa, 1999). 


\subsection{Capacidades gerenciais para implementação da estratégia}

Os dados da Figura 5 demonstram que a alta direção evidencia que se importa com a estratégia em ação (CG16 - 77,2\%). No entanto, os índices de concordância com relação aos demais itens, que abordam capacidades específicas da alta administração no que tange à implementação, são menores, entre $50 \%$ e $60 \%$, sendo inclusive menores se comparados aos outros construtos relatados até o momento.

Tais capacidades envolvem a comunicação de um senso de direção único (CG1 - 59,2\%), busca de consenso, melhoria da coordenação e colaboração efetiva entre os executivos (CG2 - 54,8\%), tomada de decisão compartilhada entre a alta e média gerências (CG3 - 52,0\%), ajuste dos recursos (CGl4 - 59,2\%) e remoção dos obstáculos à implementação da estratégia (CG5 - 60,8\%).

Esses dados corroboram resultados de pesquisas anteriores que indicam que fatores intangiveis, tais como esses que envolvem as habilidades de formulação e coordenação da estratégia, ainda não são devidamente considerados no processo estratégico (Prieto \& Carvalho, 2011). Beer \& Eisenstat $(2000,2004)$ sugerem que as organizações precisam de "coragem" para diagnosticar a existência de problemas envolvendo capacidades gerenciais de implementação da estratégia e que isso deveria ser feito em um clima aberto de diálogo sobre a estratégia,

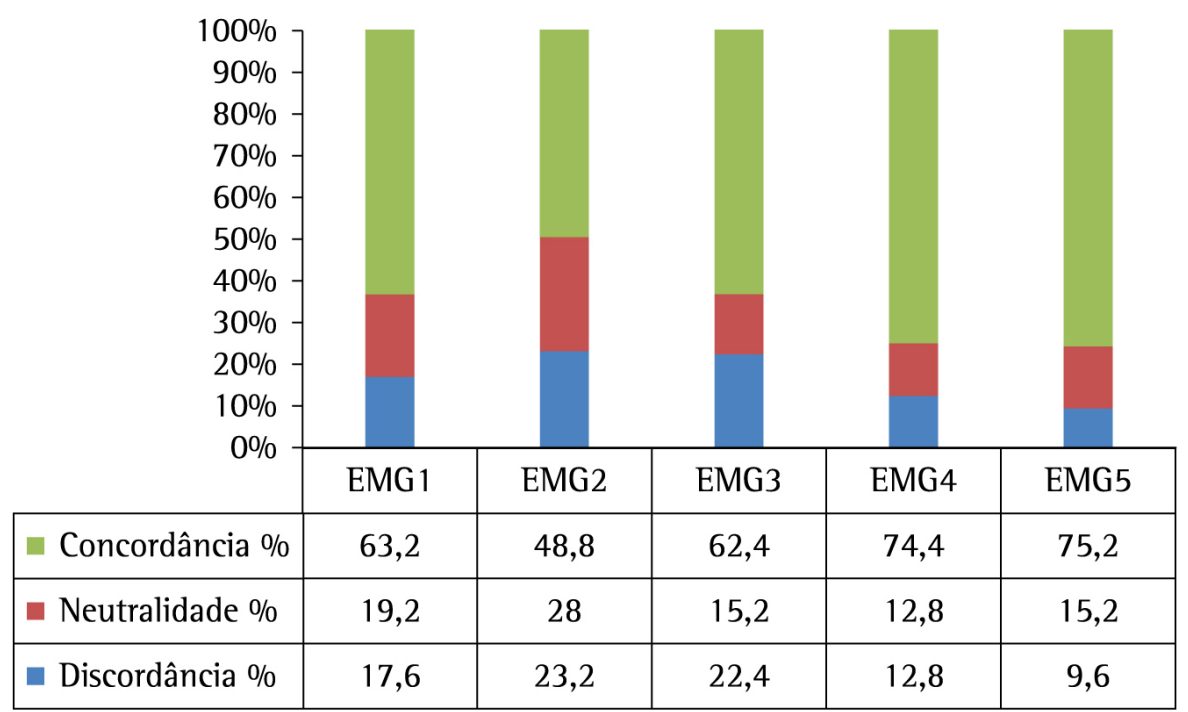

Figura 3. Dados do construto Envolvimento da média gerência na formulação da estratégia.

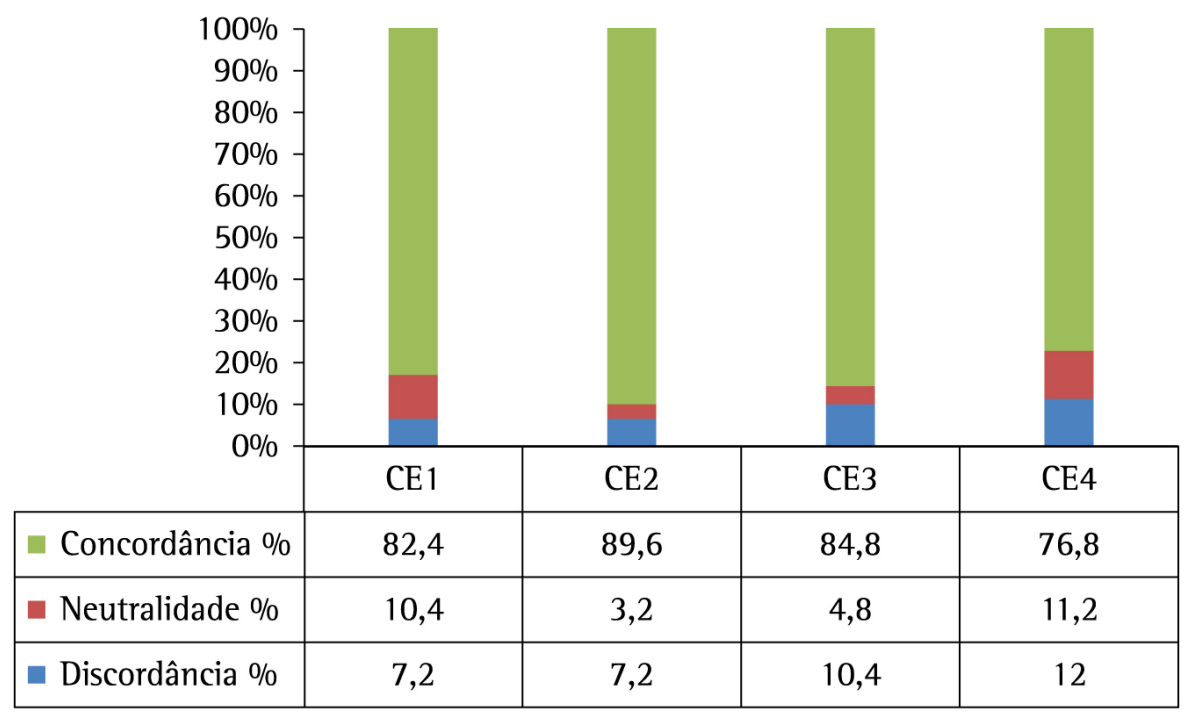

Figura 4. Dados do construto Consenso Estratégico. 
envolvendo diferentes níveis organizacionais. No entanto, os resultados dos construtos anteriores também evidenciam problemas de comunicação entre níveis hierárquicos, uma vez que não há participação ampla da média gerência na formulação da estratégia.

\subsection{Envolvimento das pessoas com a estratégia}

As estatísticas descritivas do construto EP são apresentadas na Figura 6. A concordância mais elevada dos respondentes com as assertivas EP2 $(63,2 \%)$ e EP4 $(68,5 \%)$ apontam que eles consideram que os empregados são comprometidos e mantêm um elevado senso de responsabilidade para com a empresa e que a organização como um todo se esforça para alcançar suas metas. No entanto, a média concordância $(52,4 \%)$ com a assertiva EP1 demonstra que o envolvimento dos empregados nos processos e na sua implementação pode ser melhorado.

Os índices de discordância e neutralidade com relação às assertivas EP3 $(56,8 \%)$ - compreensão das metas por todos os membros da organização, EP5 (50,4\%) - recompensa de grupos de trabalho, EP6 (48,8\%) - recompensa individual, EP7 $(56,0 \%)$ - recebimento de recompensa por parte do líder e EP8 (53,8\%) - conhecimentos e habilidades definidos a partir da estratégia da organização são indicativos dos pontos de melhoria para obter maior envolvimento dos funcionários.

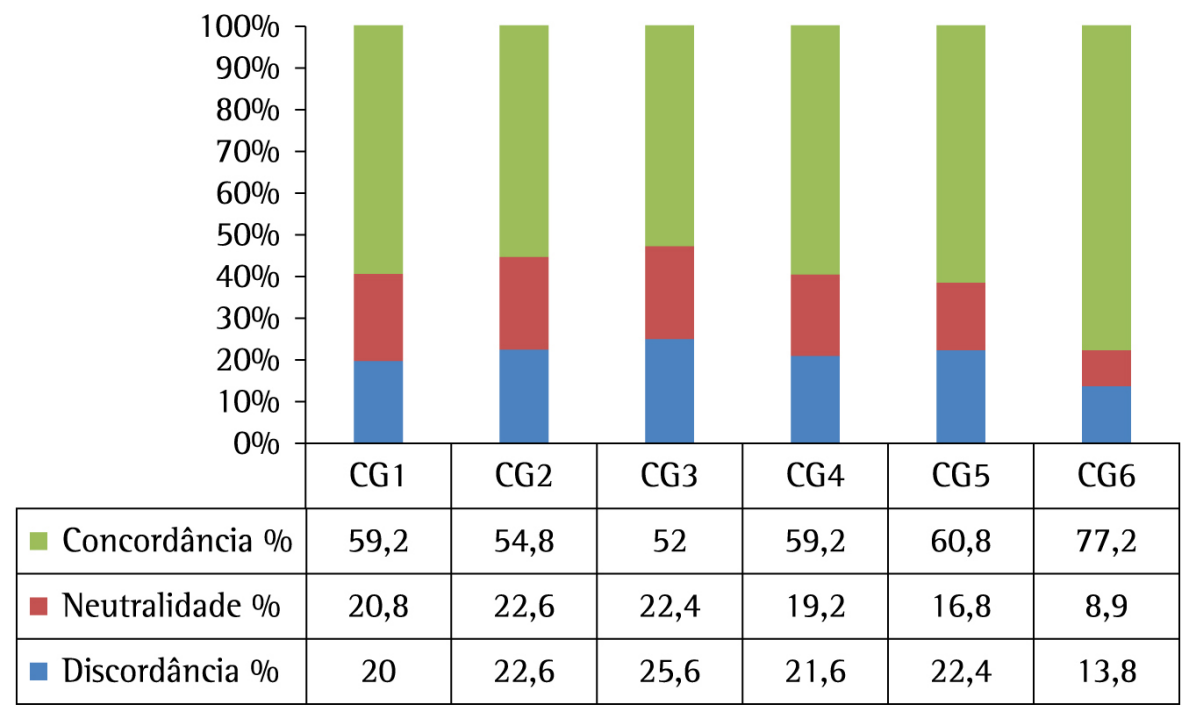

Figura 5. Dados do construto Capacidades Gerenciais para implementação.

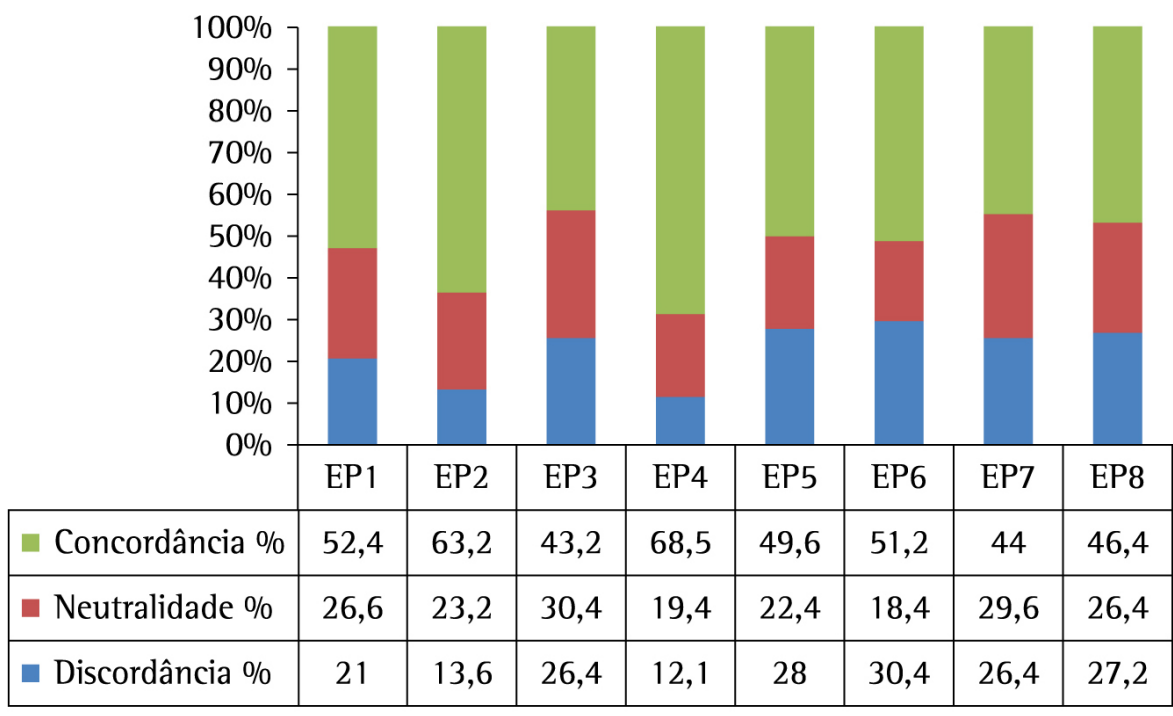

Figura 6. Dados do construto Envolvimento das Pessoas com a estratégia. 
Os dados desse construto vêm ao encontro dos resultados anteriores que indicam que a participação das pessoas no processo de alinhamento estratégico pode ser ampliada. Também evidenciam que existem falhas na criação das condições necessárias à promoção de um comportamento orientado para o alcance dos objetivos e metas.

\section{Considerações finais}

Nesse estudo, os fatores que devem ser considerados para promover o alinhamento estratégico vertical foram organizados em um framework teórico (Figura 1). Trata-se de uma contribuição ao estado da arte da literatura, uma vez que são raros os estudos que buscam a integração dos fatores necessários ao alinhamento estratégico. Uma pesquisa quantitativa foi, então, conduzida junto aos gestores para avaliar o grau de implementação dos fatores.

0 framework proposto considerou que a formulação mais abrangente da estratégia deve incluir não apenas o processo formal de planejamento (PFP), mas também o consenso estratégico (CE) e o envolvimento da média gerência (EMG).

Analisando-se a inter-relação entre os resultados desses construtos foi possível verificar que é dada maior ênfase à formalização de metas de curto prazo do que à formalização de um sistema de planejamento estratégico mais amplo, que envolva toda a organização em um período de tempo mais longo. Também foi possivel evidenciar que a natureza do planejamento afeta o grau de comunicação e participação das pessoas no processo de formulação e implementação da estratégia. Comparando-se os resultados do construto Consenso Estratégico com os resultados do construto Envolvimento da Média Gerência na formulação verifica-se que os índices de concordância dos respondentes são maiores com relação às assertivas do construto Consenso Estratégico, o que indica que a média gerência tem apoiado e dado suporte à estratégia, ainda que não participe, na mesma medida, da sua formulação, uma vez que eles tomam conhecimento da estratégia já no momento de implementá-la.

Uma das consequências da não participação da média gerência na formulação é que quando perguntados se pessoalmente estão de acordo com a estratégia em ação, o índice de concordância é o menor dentro do construto. Esse resultado corrobora a afirmação da literatura de que existe relação entre a participação da média gerência na formulação e o seu comprometimento individual com objetivos e metas organizacionais (Noble \& Mokwa, 1999).
Os construtos com maior índice de discordância e neutralidade são os de Capacidade para Implementação e Envolvimento das Pessoas. A discordância dos respondentes com relação às assertivas que mensuram as habilidades para a implementação da estratégia aponta problemas de comunicação entre a média gerência e a alta administração que estão relacionados com os gaps já apontados nos construtos Processo Formal de Planejamento e Envolvimento da Média Gerência. Se os gestores de nível médio não participam da elaboração da estratégia, eles terão que lidar com obstáculos na implementação que poderiam ter sido previstos e tratados preventivamente na formulação (Hambrick \& Cannella Junior, 1989). 0 fato de a média gerência tomar conhecimento da estratégia apenas quando da sua implementação pode diminuir o comprometimento individual com relação aos objetivos e metas estabelecidos (Noble \& Mokwa, 1999) e influenciar na habilidade de comunicar e conseguir o comprometimento das pessoas com a estratégia.

Corroborando essa afirmação, são elevados os índices de discordância dos respondentes com relação às assertivas que mensuram o envolvimento dos empregados com os processos e o seu comprometimento e senso de responsabilidade para com a organização (EP1 e EP2). Quando esses resultados são comparados aos resultados das assertivas EP5, EP6 e EP8, corroboram a afirmação teórica de que há relação entre envolvimento pessoal, sistema de recompensas e capacitação das pessoas. Nesse sentido, segundo Kaplan \& Norton (2006, p. 295), o alinhamento do capital humano é alcançado quando os objetivos individuais, programas de treinamento e remuneração estiverem alinhados com a estratégia de negócios.

Sugere-se que estudos futuros, de natureza quantitativa, mensurem o impacto das variáveis propostas no framework teórico sobre o grau de alinhamento estratégico da organização.

Estudos qualitativos poderão investigar quais ações são desenvolvidas para promover o alinhamento vertical, por exemplo: quem efetivamente participa da formulação da estratégia, como a estratégia é desdobrada, como são planejadas as ações de implementação, quais habilidades o gestor utiliza para colocar a estratégia em ação, como e quando são tratados os obstáculos à implementação.

Por fim, para se chegar ao framework especificado foi realizada e documentada uma revisão de literatura sistematizada; estudos qualitativos podem levantar outras variáveis do ponto de vista dos gestores.

Cabe ressaltar que outros fatores considerados no alinhamento estratégico vertical foram identificados 
e não foram abordados por estarem fora do escopo desta pesquisa, podendo ser abordados em estudos posteriores. Por exemplo, no trabalho de Carmeli \& Tishler (2004) - auditoria interna, capital humano, percepção da reputação organizacional; no trabalho de Chan et al. (2006) - sucesso anterior na implementação da estratégia e tamanho da organização; no trabalho de Noble \& Mokwa (1999) - autonomia pessoal, comprometimento individual, fatores da estratégia - envolvimento das áreas e existência de um líder campeão e importância pessoal e no trabalho de Powell (1992)-locus de controle interno do CEO, formalização da estrutura e estabilidade ambiental.

\section{Referências}

Asato, R., Spinola, M. M., Costa, 1., \& Silva, W. H. F. (2011). Alinhamento entre estratégia de negócios e melhoria de processos de software: um roteiro de implementação. Produção, 21(2), 314-328. http://dx.doi.org/10.1590/ S0103-65132011005000028

Atkinson, H. (2006). Strategy implementation: a role for the balanced scorecard? Management Decision, 44(10), 14411460. http://dx.doi.org/10.1108/00251740610715740

Barney, J. B., \& MacKey, T. B. (2005). Testing resourcebased theory. In D. J. Ketchen, \& D. D. Bergh (Eds.) Research metodology in strategy and management. Oxford: Elsevier. http://dx.doi.org/10.1016/S14798387(05)02001-1

Beer, M., \& Eisenstat, R. A. (2000). The silent killers of strategy implementation and learning. Sloan Management Review, 41(4), 29-40.

Beer, M., \& Eisenstat, R. A. (2004). How to have an honest conversation about your business strategy. Harvard Business Review, 82-89. PMid:14971272.

Boswell, W. (2006). Aligning employees with the organization's strategic objectives: out of 'line of sight', out of mind. International Journal of Human Resource Management, 1799), 1489-1511. http://dx.doi. org/10.1080/09585190600878071

Boswell, W. R., \& Boudreau, J. W. (2001). How leading companies create, measure and achieve strategic results through "line of sight". Management Decision, 39(10), 851-859. http://dx.doi.org/10.1108/ EUM0000000006525

Camelo, C., Fernandez-Alles, M., \& Hernandez, A. B. (2010). Strategic consensus, top management teams, and innovation performance. International Journal of Manpower, 31(6), 678-695. http://dx.doi. org/10.1108/01437721011073373

Campbell, A., \& Alexander, M. (1997). What's wrong with strategy? Harvard Business Review, 42-51. PMid:10174797.

Carmeli, A., \& Tishler, A. (2004). The relationships between intangible organizational elements and organizational performance. Strategic Management Journal, 25(13), 1257-1278. http://dx.doi.org/10.1002/ smj. 428

Carvalho, M. M., Prieto, V. C., \& Bouer, R. (2013). Maximização da estratégia: promovendo resultados por meio do alinhamento, execução e medição. Rio de Janeiro: Elsevier.

Chan, Y. E., Sabherwal, R., \& Thatcher, J. B. (2006). Antecedents and outcomes of strategic IS alignment: An empirical investigation. IEEE Transactions on Engineering Management, 53(1), 27-47. http://dx.doi. org/10.1109/TEM.2005.861804

Chandler, A. D. (1962). Strategy and structure: chapters in the history of the industrial enterprise. Cambridge: MIT Press.

Chen, D. Q., Mocker, M., Preston, D. S., \& Teubner, A. (2010). Information systems strategy: reconceptualization, measurement, and implications. Mis Quarterly, 34(2), 233259.

Creswell, J. W. (2007). Projeto de pesquisa: métodos qualitativo, quantitativo e misto. Porto Alegre: Artmed.

Decoene, V., \& Bruggeman, W. (2006). Strategic alignment and middle-level managers' motivation in a balanced scorecard setting. International Journal of Operations \& Production Management, 26(3-4), 429-448 . http:// dx.doi.org/10.1108/01443570610650576

Fleury, A. C., \& Fleury, M. T. L. (2000). Estratégias empresariais e formação de competências. São Paulo: Atlas.

Floyd, S. W., \& Wooldridge, B. (1992a). Middle management involvement in strategy and its association with strategic type: a research note. Strategic Management Journal, 13(8), 153-167. http://dx.doi.org/10.1002/ smj.4250131012

Floyd, S. W., \& Wooldridge, B. (1992b). Managing strategic consensus: the foundation of effective implementation. Academy of Management Executive, 6(4), 27-39.

Forza, C. (2002). Surveys research in operations management: a process-based perspective. International Journal of Operations \& Production Management, 22(2), 152-194. http://dx.doi.org/10.1108/01443570210414310

Gagnon, M., Jansen, K., \& Michael, J. (2008). Employee Alignment with Strategic Change: a study of strategysupportive behavior among blue-collar employees. Journal of Managerial lssues, 20(4), 425.

Galbraith, J. R. (1977). Organization design. Reading: Addison-Wesley Pub Co.

Ginsberg, A., \& Venkatraman, N. (1985). Contingency perspectives of organizational strategy: a critical review of the empirical Research, Academy of Management. Academy of Management Review, 10(3), 421-434.

Gonzalez-Benito, J., Aguinis, H., Boyd, B. K., \& SuárezGonzález, 1. (2012). Coming to Consensus on Strategic Consensus: A Mediated Moderation Model of Consensus and Performance. Journal of Management, 38(6), 16851714. http://dx.doi.org/10.1177/0149206310386489

Grant, R. M. (1991). The resource-based theory of competitive advantage: implications for strategy formulation. California Management Review, 33(3), 114-135. http:// dx.doi.org/10.2307/41166664

Hair Junior, J. F., Anderson, R. E., Tatham, R. L., \& Black, W. C. (2009). Análise muitivariada de dados. (6 ed.). Porto Alegre: Bookman.

Hambrick, D. C., \& Cannella Junior, A. A. (1989). Strategy implementation as substance and selling. Academy of Management Executive, 3(4), 278-285. http://dx.doi. org/10.5465/AME. 1989.4277401 
Hill, A., \& Cuthbertson, R. (2011). Fitness map: a classification of internal strategic fit in service organisations. International Journal of Operations \& Production Management, 31(9-10), 991-1020. http://dx.doi. org/10.1108/01443571111165857

Hitt, M. A., Ireland, R. D., \& Hoskisson, R. E. (2008). Administração estratégica: competitividade e globalização (2. ed.). São Paulo: Thomson Learning.

Hitt, M. A., Et lreland, R. D. (1985). Corporate distinctive competence, strategy, industry and performance. Strategic Management Journal, 6(3), 273-293. http:// dx.doi.org/10.1002/smj.4250060307

Hitt, M., A., Ireland, R. D., \& Palia, K. A. (1982). Industrial firms' grand strategy and functional importance: Moderating effects of technology and uncertainty. Academy of Management Journal, 25(2), 265-298. http://dx.doi.org/10.2307/255990

Hrebiniak, L. G. (2006). Fazendo a estratégia funcionar: o caminho para uma execução bem-sucedida. Porto Alegre: Bookman.

Hrebiniak, L. G., \& Joyce, W. F. (2001). Implementing Strategy: An appraisal and agenda for future Research. In M. Hitt, R. E. Freeman \& J. Harrison (Eds.), Handbook of Strategic Management (pp. 602-626). 0xford: Blackwell Business.

Joshi, M. P., Kathuria, R., \&t Porth, S. J. (2003). Alignment of strategic priorities and performance: an integration of operations and strategic management perspectives. Journal of Operations Management, 21(3), 353-369. http://dx.doi.org/10.1016/S0272-6963(03)00003-2

Kaplan, R. S., \& Norton, D. P. (1996). Using the balanced scorecard as a strategic management system. Harvard Business Review, 74(1), 75-85.

Kaplan, R. S., \& Norton, D. P. (2000). Having Trouble With Your Strategy? Then map it. Harvard Business Review, 78(5), 167-176. PMid:11143152.

Kaplan, R. S., \& Norton, D. P. (2006). Alinhamento: Utilizando $o$ balanced scorecard para criar sinergias corporativas. Rio de Janeiro: Elsevier.

Kathuria, R., Joshi, M. P., \& Porth, S. J. (2007). Organizational alignment and performance: past, present and future. Management Decision, 45(3), 503-517. http://dx.doi. org/10.1108/00251740710745106

Kellermanns, F. W., Walter, J., \& Floyd, S. W. (2011). To agree or not to agree? A meta-analytical review of strategic consensus and organizational performance. Journal of Business Research, 64(2). http://dx.doi.org/10.1016/j. jbusres.2010.02.004

Kraatz, M. S., \& Zajac, E. J. (2001). How organizational resources affect strategic change and performance in turbulent environments: Theory and evidence. Organization Science, 12(5), 632-657. http://dx.doi. org/10.1287/orsc. 12.5.632.10088

Labovitz, G., \& Rosansky, V. (1997). The power of alignment: how great companies stay centered and accomplish extraordinary things. New York: John Wiley \& Sons.

Malina, M. A., \& Selto, F. H. (2001). Communicating and controlling strategy: an empirical study of the effectiveness of the balanced scorecard. Journal of Management Accounting Research, 13, 47-90. http:// dx.doi.org/10.2308/jmar.2001.13.1.47

Miles, R. H., \& Snow, C. C. (1978). Organizational strategy, structure and process. New York: McGraw-Hill.
Miller, D. (1987). The structural and environmental correlates of business strategy. Strategic Management Journal, 8(1), 55-76. http://dx.doi.org/10.1002/smj.4250080106

Mintzberg, H. (1994). The fall and rise of strategic planning. Harvard Business Review, 107-114.

Mintzberg, H., \& Waters, J. A. (1985). Of strategies, deliberate and emergent. Strategic Management Journal, 6(3), 257272. http://dx.doi.org/10.1002/smj.4250060306

Monteiro de Barros, L. A. (2007). Alinhamento estratégico (Tese de doutorado). Faculdade de Economia, Administração e Contabilidade, Universidade de São Paulo, São Paulo, 2007. Recuperado em 2 de agosto de 2012, de http://www. teses.usp.br/teses/disponiveis/12/12139/ tde-06052007- 141720/

Neely, A. (2005). The evolution of performance measurement research: developments in the last decade and a research agenda for the next. International Journal of Operations \& Production Management. 25(12), 1264-1277. http:// dx.doi.org/10.1108/01443570510633648

Noble, C. H. (1999). The eclectic roots of strategy implementation. Journal of Business Research, 45, 119134. http://dx.doi.org/10.1016/S0148-2963(97)00231-2

Noble, C. H., \& Mokwa M. P. (1999). Implementing marketing strategies: Developing and testing a managerial theory. Journal of Marketing, 63(4), 57-73. http://dx.doi. $\operatorname{org} / 10.2307 / 1251974$

Oliveira, L. R., Medeiros, R. M., Terra, P. B., \& Quelhas, O. L. G. (2012). Sustentabilidade: da evolução dos conceitos à implementação como estratégia nas organizações. Produção, 22(1). http://dx.doi.org/10.1590/S010365132011005000062

Parish, J. T., Cadwallader, S., \& Busch, P. (2008). Want to, need to, ought to: employee commitment to organizational change. Journal of Organizational Change Management, 21(1), 32-52. http://dx.doi. org/10.1108/09534810810847020

Peters, T., \& Waterman, R. (1982). In Search of Excellence: lessons from America's best-run companies. New York: Time Warner.

Powell, T. C. (1992) Organizational alignment as competitive advantage. Strategic Management Journal, 13(2), 119134. http://dx.doi.org/10.1002/smj.4250130204

Prieto, V. C. (2011). Impacto do alinhamento da estratégia de negócios sobre o desempenho (Tese de doutorado). Escola Politécnica, Universidade de São Paulo, São Paulo.

Prieto, V. C., \& Carvalho, M. M. (2011). Strategic alignment and performance: Brazilian companies in the medical diagnostics sector. The Service Industries Journal, 31(9), 1405-1427. http://dx.doi. org/10.1080/02642060903576050

Prieto, V. C., Carvalho, M. M., \& Fischmann, A. A. (2009). Análise comparativa de modelos de alinhamento estratégico. Produção, 19(2), 317-331. http://dx.doi. org/10.1590/S0103-65132009000200008

Rapert, M. 1., Velliquette, A., \& Garretson, J. A. (2002). The strategic implementation process - Evoking strategic consensus through communication. Journal of Business Research, 55(4), 301-310. http://dx.doi.org/10.1016/ S0148-2963(00)00157-0

Siggelkow, N. (2002). Evolution toward fit. Administrative Science Quarterly, 47(1), 125-159. http://dx.doi. $\operatorname{org} / 10.2307 / 3094893$ 
Speckbacher, G., Bischof, J., \& Pfeiffer, T. (2003). A descriptive analysis on the implementation of balanced scorecards in german-speaking countries. Management Accounting Research, 14(4), 361-887. http://dx.doi.org/10.1016/j. mar.2003.10.001

Venkatraman, N., \& Camillus, J. C. (1984). Exploring the concept of 'fit' in strategic management. Academy of Management Review, 9(3), 513-525.

Xu, S. C., Cavusgil, S. T., \& White, J. C. (2006). The impact of strategic fit among strategy, structure, and processes on multinational corporation performance: A multimethod assessment. Journal of International Marketing, 14(2), 1-31. http://dx.doi.org/10.1509/ jimk.14.2.1

White, G. O., Hadjimarcou, J., Fainshmidt, S., \& Posthuma, R. A. (2013). MNE home country cultural norms and conflict strategy fit in transnational business contract disputes. International Business Review, 22(3), 554-567. http://dx.doi.org/10.1016/j.ibusrev.2012.08.001
Wong, T. C., Ngan, S.-C. \& Chan, F. T. S. A. (2012). Twostage analysis of the influences of employee alignment on effecting business-IT alignment. Decision Support Systems. 53(3), 490-498. http://dx.doi.org/10.1016/j. dss.2012.03.008

Wooldridge, B., \& Floyd, S. W. (1990). The Strategy Process, Middle Management Involvement and Organizational Performance. Strategic Management Journal, 11(3), 231241. http://dx.doi.org/10.1002/smj.4250110305

Zaefarian, G., Henneberg, S. C., \& Naudé, P. (2013). Assessing the strategic fit between business strategies and business relationships in knowledge-intensive business services. Industrial Marketing Management, 42(2), 260-272. http://dx.doi.org/10.1016/j.indmarman.2012.08.008

Zajac, E. J., Kraatz, M. S., \& Bresser, R. K. F. (2000). Modeling the dynamics of strategic fit: A normative approach to strategic change. Strategic Management Journal, 21(4), 429-453. http://dx.doi.org/10.1002/ (SICl) $1097-0266(200004) 21: 4<429:$ :A1D SMJ81>3.0.CO;2-\#

\title{
Key factors for the vertical strategic alignment: a survey with Brazilian executives
}

\begin{abstract}
Alignment is a central concept in the field of strategy studies. However, prior research has tended to emphasize the subject in the context of the formulation versus the implementation of strategy. This study contributes to filling this gap by identifying and proposing a framework with key factors to promote strategic vertical alignment. These factors were submitted to 125 Brazilian executives in a quantitative study to evaluate their implementation. The results were evaluated by applying descriptive statistics. The results demonstrated an emphasis on short-term planning, a need to extend the participation of middle management in the formulation process, and gaps in management's capacity to implement strategy. Factors that can enhance people's involvement with the strategy are also discussed.
\end{abstract}

Keywords

Strategic alignment. Vertical strategic alignment. Business strategy. Strategy implementation. 


\section{Anexo 1. Questionário e valores do Alpha de Cronbach}

\begin{tabular}{|c|c|}
\hline \multicolumn{2}{|r|}{ Processo Formal de Planejamento $(0,777)$} \\
\hline PFP1 & Ações baseadas em planos formais \\
\hline PFP2 & Objetivos formalizados e conhecidos \\
\hline PFP3 & Metas formalizadas e conhecidas pelos gerentes \\
\hline PFP4 & Sistema de planejamento estratégico para toda a organização \\
\hline PFP5 & Plano estratégico formalizado para o próximo exercício \\
\hline PFP6 & Equipe encarregada da elaboração de um plano estratégico \\
\hline PFP7 & Encontros gerenciais regulares para discutir a estratégia como um todo \\
\hline \multicolumn{2}{|r|}{ Envolvimento da Média Gerência (EMG) na formulação $(0,860)$} \\
\hline EMG1 & MG e superiores decidem juntos o que será feito para a implementação \\
\hline EMG2 & MG toma conhecimento da estratégia com antecedência \\
\hline EMG3 & Durante a implementação, MG pode sugerir mudanças aos superiores \\
\hline EMG4 & Responsabilidades da MG, na implementação, são significativas \\
\hline EMG5 & MG é peça chave para a implementação da estratégia \\
\hline \multicolumn{2}{|r|}{ Consenso Estratégico $(0,865)$} \\
\hline CE1 & A estratégia em ação é relevante para a missão da empresa \\
\hline CE2 & É esperado que a estratégia afete positivamente o futuro da empresa \\
\hline CE3 & Eu penso que a estratégia está de acordo com os interesses da empresa \\
\hline CE4 & Eu pessoalmente sinto que os objetivos relacionados são apropriados \\
\hline \multicolumn{2}{|r|}{ Capacidades Gerenciais para a implementação da estratégia $(0,869)$} \\
\hline CG1 & Alta administração desenvolve senso de direção único \\
\hline CG2 & Executivos buscam obter, entre si, o consenso \\
\hline CG3 & Uso da tomada de decisão compartilhada entre a alta administração e a MG \\
\hline CG4 & Executivos promovem os ajustes dos recursos para a implementação \\
\hline CG5 & Executivos buscam identificar os obstáculos à implementação \\
\hline CG6 & Alta direção evidencia que se importa com a estratégia em ação \\
\hline \multicolumn{2}{|r|}{ Envolvimento das Pessoas com a estratégia $(0,875)$} \\
\hline EP1 & Alto envolvimento dos empregados nos processos e na sua implementação \\
\hline EP2 & Empregados comprometidos e com elevado senso de responsabilidade \\
\hline EP3 & Metas compreendidas por todos os membros \\
\hline EP4 & Organização como um todo se esforça para alcançar suas metas \\
\hline EP5 & Grupos de trabalho recompensados por seu desempenho \\
\hline EP6 & Organização recompensa o desempenho individual \\
\hline EP7 & Líderes recompensam o bom desempenho dos funcionários \\
\hline EP8 & Conhecimentos e habilidades definidos a partir da estratégia \\
\hline
\end{tabular}

